\title{
Spontaneous oesophageal perforation in an infant
}

\author{
Jai Prakash Soni ${ }^{1}$, *Sandeep Choudhary ${ }^{1}$, Suresh Verma ${ }^{1}$, Subhash Balara ${ }^{1}$, Manoj Kamal ${ }^{1}$
}

Sri Lanka Journal of Child Health, 2017; 46(2): 192-194

DOI: http://dx.doi.org/10.4038/sljch.v46i2.8283

(Key Words: Infant, oesophageal perforation, oesophageal-pleural fistula, mediastinitis)

\section{Introduction}

Common causes of oesophageal perforation in children are traumatic, iatrogenic (oesophageal dilation, endoscopy, gastric tube insertion, endotracheal intubation, forceful oropharyngeal suctioning and transesophageal echocardiography), spontaneous or following forceful vomiting ${ }^{1,2}$. Surgical intervention is the preferred approach in adults and haemodynamically unstable children ${ }^{3}$. We report a case of spontaneous oesophageal perforation in an infant which was diagnosed promptly and managed successfully.

\section{Case report}

A one year old unimmunized male child, belonging to a low socioeconomic family was admitted to our institution with a history of fever, loose motions, nonspasmodic cough and not gaining weight. On admission, his weight, head circumference, height and mid arm circumference were $3.5 \mathrm{~kg}, 36 \mathrm{~cm}, 67 \mathrm{~cm}$ and $10 \mathrm{~cm}$ respectively. Child was malnourished, conscious and irritable. His vital signs were stable. His airway was patent and no respiratory distress was seen but air entry was found to be significantly less in the right lung with a dull note on percussion. His haemoglobin was $7 \mathrm{~g} \%$ and the total leucocyte count 7100/cu mm (P55, L 38). His liver and renal function tests were normal. X-ray chest PA view revealed right sided hydro-pneumothorax (figure 1A). An intercostal drainage tube was inserted and surprisingly, a large amount of milk came out of the intercostal tube. Contrast oesophagography (figure 1B) showed dye in pleural cavity.

${ }^{1} \mathrm{Dr} S \mathrm{~N}$ Medical College, India

*Correspondence: sandeepbugasara@gmail.com (Received on 18 February 2016: Accepted after revision on 22 April 2016)

The authors declare that there are no conflicts of interest

Personal funding was used for this project.

Open Access Article published under the Creative

Commons Attribution CC-BY CC License.

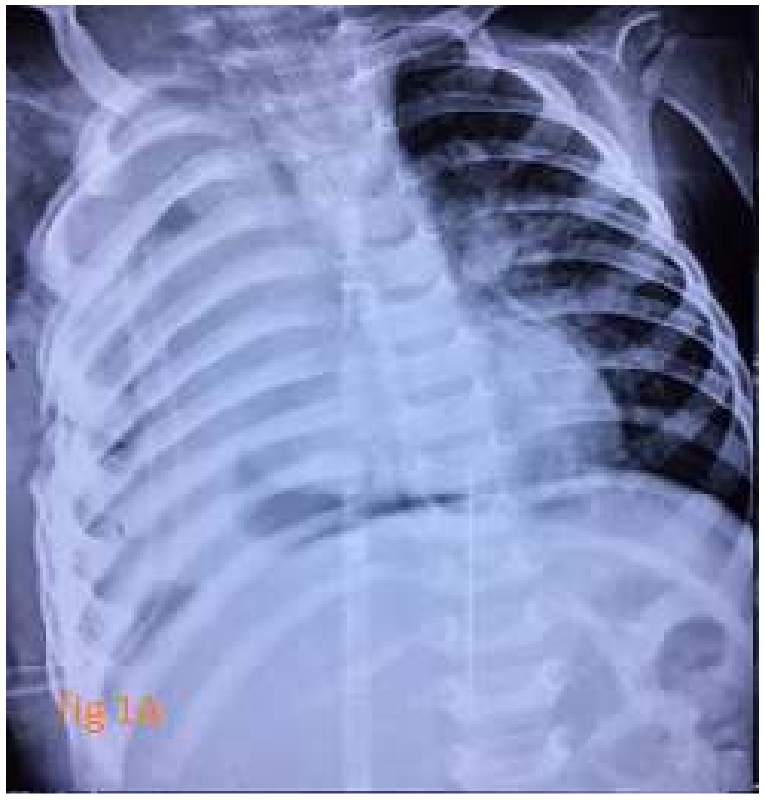

Figure 1A: X-ray chest showing pleural effusion (right side)

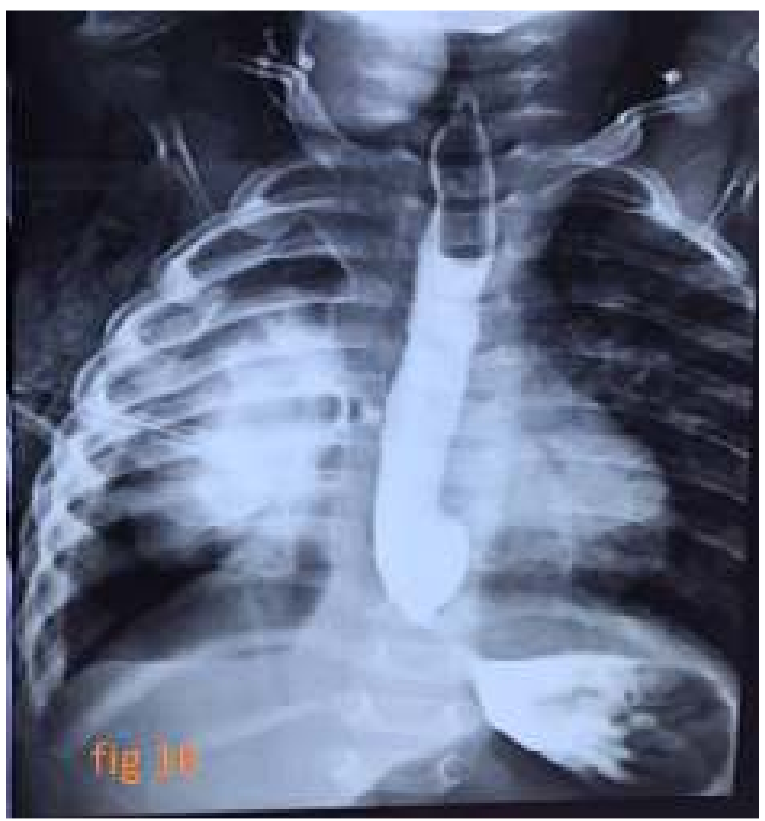

Figure 1B: Contrast oesophagography showing dye in $(R)$ pleural cavity 
Contrast enhanced computed tomography of chest with additional non-ionic contrast given orally revealed right sided hydro-pneumothorax with accumulation of contrast in right pleural cavity (figure $1 \mathrm{C})$.

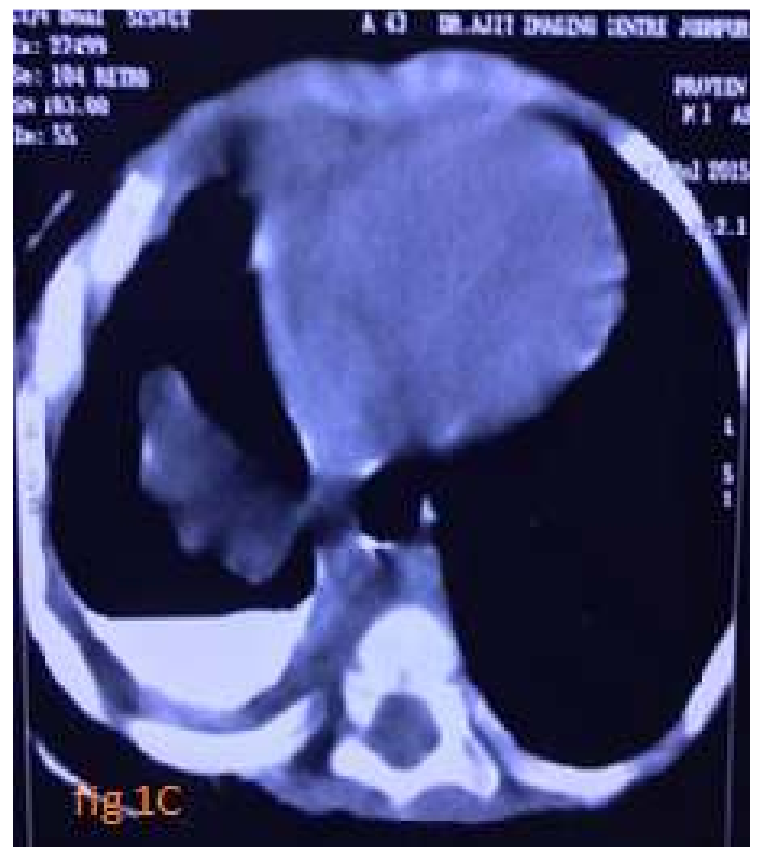

Figure 1C: Contrast enhanced computed tomography of chest depicting dye in (R) pleural cavity

Thus we made a provisional diagnosis of idiopathic oesophageal-right pleural fistula, as there was no history of upper GI endoscopy, instrumentation or trauma. Child was kept nil orally and treated with IV fluids, parenteral nutrition (amino acid and lipid) and IV antibiotics (meropenem, linezolid) for two weeks but no improvement was seen in review contrast oesophagography. Thus, right lateral thoracotomy was planned. Thoracotomy revealed thick pleura, collapsed lung and longitudinal perforation in thoracic oesophagus about $1.5 \times 1.0 \mathrm{~cm}$ at level of D4 (figure 1D).

Decortication of pleura was done and the oesophageal perforation was repaired. Child was kept in the intensive care unit postoperatively for three days and treated with parenteral fluid, antibiotics, aminoacids and intralipid infusion. Nasogastric feeding was started on the $5^{\text {th }}$ postoperative day and oral feeding on $7^{\text {th }}$ postoperative day. Patient responded to treatment dramatically and on discharge his weight was $4.5 \mathrm{~kg}$.

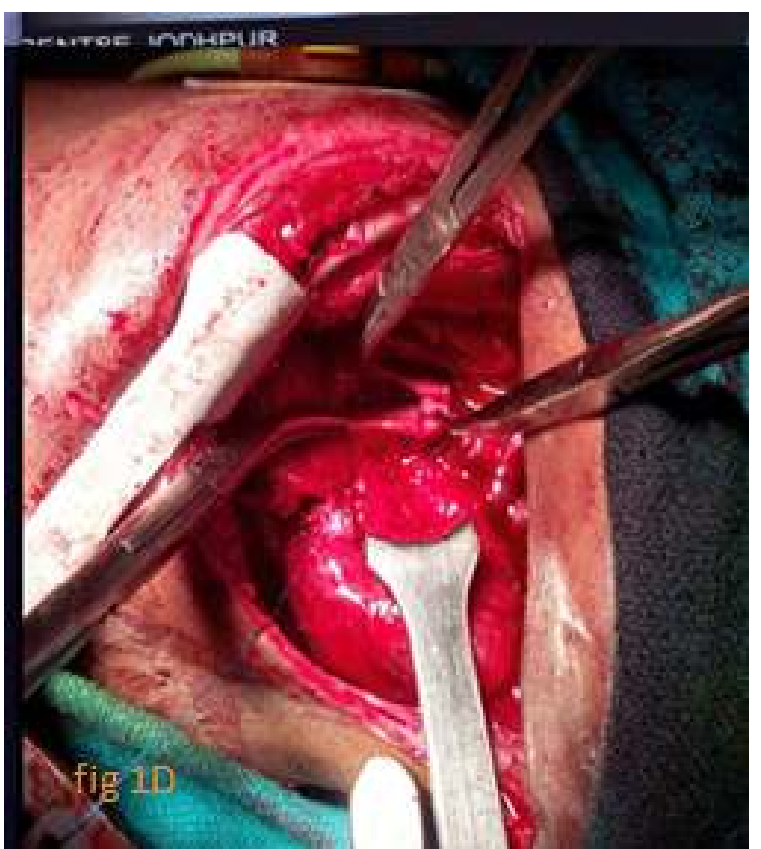

Figure 1D: Intra-operative picture showing hole in oesophagus at D4 level

\section{Discussion}

Oesophageal perforation was first described in the late 18 th century by Boerhaave ${ }^{4}$. The first paediatric perforation was described by Fryfogle in $1952^{5}$. Clinical manifestations of early oesophageal perforation can be vague and nonspecific (pain, fever, dysphagia, dyspnea and subcutaneous emphysema). A high index of suspicion is required to prevent delay in diagnosis and to improve the prognosis 6 . Reported mortality rates in the literature are $0-18 \%$ in early diagnosis and $7-37.5 \%$ in late diagnosis ${ }^{7}$. The mortality rate was higher with a spontaneous rupture of the esophagus compared with an iatrogenic and traumatic rupture $(36 \% \text { versus } 19 \% \text { versus } 7 \%)^{2}$.

Chest x-rays, water soluble or non-ionic contrast oesophagography and contrast enhanced CT scan with oral contrast are the modalities of choice for early and accurate diagnosis ${ }^{8}$. Surgery is the preferred modality of treatment for haemodynamically unstable patients. Paediatric and haemodynamically stable patients can be managed with a non-operative approach as healing capacity of tissues is good at a younger age ${ }^{3}$. With recent advances in treatment of oesophageal perforations, many studies use endoscopically placed self-expandable metallic stents with or without chest drainage $^{7}$. As our case belonged to the younger age and was haemodynamically stable we tried to manage conservatively but the perforation was not healed and hence we managed the case surgically and the patient was discharged from the ward in a stable condition. 


\section{References}

1. Asensio JA, Chahwan S, Forno W, MacKersie R, Wall M, Lake J, et al. Penetrating oesophageal injuries. Multicenter study of the American Association for the Surgery of Trauma. Journal of Trauma 2001; 50(2):289-96.

https://doi.org/10.1097/00005373200102000 $-00015$

PMid: 11242294

2. Brinster CJ, Singhal S, Lee L, Marshall MB, Kaiser LR, Kucharczuk JC. Evolving options in the management of oesophageal perforation. Annals of Thoracic Surgery 2004; 77(4):1475-83.

https://doi.org/10.1016/j.athoracsur.2003.08. 037

PMid: 15063302

3. Gander JW, Berdon WE, Cowles RA. Iatrogenic esophageal perforation in children. Pediatric Surgery International 2009; 25(5):395-401.

https://doi.org/10.1007/s00383-009-2362-6

PMid: 19381653

4. Derbes VJ, Mitchell RE. Hermann Boerhaave's Atrocis, nec descripti prius, morbi historia, the first translation of the classic case report of rupture of the esophagus, with annotations. Bulletin of the Medical Library Association 1955; 43:21740.

PMid: 14364044 PMCid: PMC199852
5. Fryfogle J. Discussion of paper by RL Anderson: Rupture of the oesophagus. Journal of Thoracic Surgery 1952; 24:36988.

6. Port JL, Kent MS, Korst RJ, Bacchetta M, Altorki NK. Thoracic esophageal perforations: a decade of experience. Annals of Thoracic Surgery 2003; 75(4):1071-4. https://doi.org/10.1016/S00034975(02)0465 $0-7$

7. Sengul AT, Buyukkarabacak YB, Yetim TD, Pirzirenli MG, Celik B and Basoglu A. Early diagnosis saves lives in oesophageal perforations. Turkish Journal of Medical Sciences 2013; 43:1-7.

8. Soreide JA and Viste A. Oesophageal perforation: Diagnostic work-up and clinical decision-making in the first 24 hours. Scandinavian Journal of Trauma, Resuscitation and Emergency Medicine 2011; 19: 1-7.

https://doi.org/10.1186/1757-7241-19-66

PMid: 22035338 PMCid: PMC3219576 